\title{
Rare Complication of Nasogastric Tube Knotting around Endotracheal Tube in an Anesthetized Patient Undergoing Surgery
}

\author{
Suvidha Sood ${ }^{1}$ Yeesha Aggarwal ${ }^{1}$ Anoj Kumar ${ }^{1}$ \\ ${ }^{1}$ Department of Anaesthesia, ESIC Medical College and Hospital, \\ New Delhi, India
}

\begin{abstract}
Address for correspondence Suvidha Sood, House Number 8 , Second Floor, Pocket -1, Sector -21, Rohini, New Delhi 110086, India (e-mail: suvidhasood1962@gmail.com).
\end{abstract}

\begin{abstract}
Keywords

- Ryle's tube

- knotting

- endotracheal tube

We report a case of successful management of a rare incidence and avoidance of complication of Ryle's tube knotting around endotracheal tube. A vigilant anesthesia team prevented fatal complications of intraoperative accidental extubation and ventilation impairment which could have resulted into respiratory distress.
\end{abstract}

\section{Introduction}

Since the nasogastric tube is flexible and must undergo a significant bend in the oropharynx, it is impossible to precisely control the position of the end of the tube. There is considerable risk that the tube gets coiled in the mouth or enters the trachea, neighboring structures and lung instead of the esophagus. ${ }^{1}$ When the gastric tube is placed orally or nasally, it enters the hypopharynx invariably and impacts the structures thereby coiling in the mouth. ${ }^{2}$ There are many chances that the Ryle's tube can get coiled during its passage in the oral cavity, but in our case a very rare incidence of unusual coiling of Ryle's tube occurred around the endotracheal tube (ETT).

\section{Case Report}

A 72-year-old male patient with a chief complaint of pain abdomen was diagnosed as cholecystitis with pseudopancreatic cyst of pancreas. He was scheduled to undergo transgastric cystogastrostomy under general anesthesia with muscle relaxation and intermittent positive pressure ventilation. An $8.5-\mathrm{mm}$ internal diameter cuffed Murphy-eye blue line orotracheal tube was placed under

\section{published online} April 13, 2021
DOI https://doi.org/

10.1055/s-0041-1726153 ISSN 0379-038X. direct laryngoscopy and secured at $21 \mathrm{~cm}$ mark at the right angle of mouth. Mechanical ventilation was initiated and the patient's vital parameters were observed to be within normal limits.

Immediately after initiation of surgery, we tried to insert the nasogastric tube to decompress the stomach during cholecystectomy. With patient's head flexed, a lubricated 16 FG nasogastric tube was blindly inserted via the right nares. We encountered resistance during advancement of Ryle's tube. The nasogastric tube could not be advanced further into the oral cavity despite our best efforts. So, we decided to remove the Ryle's tube. We noticed that it was getting tethered during the attempts of its removal. Moreover during the entire maneuver of pulling it out, the ETT was also getting pulled out along with the Ryle's tube. About $1 \mathrm{~cm}$ of ETT tube got displaced and pulled outside while we were trying to remove the Ryle's tube (en masse along with ETT tube). We made several unsuccessful attempts to withdraw the nasogastric tube, but failed and felt resistance each time. It was noticed that ETT was moving in tandem with the nasogastric tube, inside oral cavity. With hand palpation, a hard structure was felt knotted around the ETT, possibly the Ryle's tube. The stomach could not be decompressed and the gastric fluid was not aspirated. (c) 2021. National Academy of Medical Sciences (India).

This is an open access article published by Thieme under the terms of the Creative Commons Attribution-NonDerivative-NonCommercial-License, permitting copying and reproduction so long as the original work is given appropriate credit. Contents may not be used for commercial purposes, or adapted, remixed, transformed or built upon. (https://creativecommons.org/licenses/by-nc-nd/4.0/).

Thieme Medical and Scientific Publishers Pvt. Ltd. A-12, 2nd Floor, Sector 2, Noida-201301 UP, India 
Under direct laryngoscopic view, a clear knot around the ETT at a length of $14 \mathrm{~cm}$ mark was seen on the ETT. This was confirmed with fiberoptic bronchoscopy later ( - Fig. 1). To decompress the stomach, another nasogastric tube was inserted through left nares, which went easily without any resistance with gastric contents coming out of it. This proved that the left intraoral passage for Ryle's tube insertion was clear and previous Ryle's tube was not encroaching upon it.

Patient's hemodynamic parameters remained stable throughout the procedure. During the surgery, patient's systolic blood pressure varied between 110 and $130 \mathrm{~mm} \mathrm{Hg}$ and diastolic between 70 and $90 \mathrm{~mm} \mathrm{Hg}$, pulse rate between 70 and 90 beats per minute, regular. Peak airway pressure remained between 18 and $20 \mathrm{~cm} \mathrm{H}_{2} \mathrm{O}$. A normal capnographic wave form was present. Oxygen saturation was between 98 and $100 \%$ throughout the procedure. After completion of surgery, both the previously inserted right sided Ryle's tube and the ETT were removed together en bloc.

Thus, a fatal intraoperative mishap of accidental intraoperative extubation and respiratory distress was prevented by the vigilance of anesthesia team. Thus, we were able to successfully avoid any complication of Ryle's tube knotting around ETT further, which could have resulted in an untoward incidence of ventilation impairment or damage to neighboring structures by its coiling.

After diagnosing nasogastric tube coiled around the ETT, further possibility to untie or manipulate it did not exist in our case, because both the tubes were moving together. The ETT did not get compressed during the entire process as evident from the patient's respiratory parameters. No change was noticed in patient's capnography, peak airway pressure, and pulse oximetry. So, tracheal extubation and reintubation were not considered.

With finger manipulation, the proximal end of the nasogastric tube was brought out through the mouth to assist in removing nasogastric tube and ETT tube together en masse after the surgery. In in vitro examination, nasogastric tube was found tightly knotted around but not strangulating the tracheal tube just below the $15-\mathrm{cm}$ mark, measured $20 \mathrm{~cm}$ from the tip of the nasogastric tube ( - Fig. 2 ).

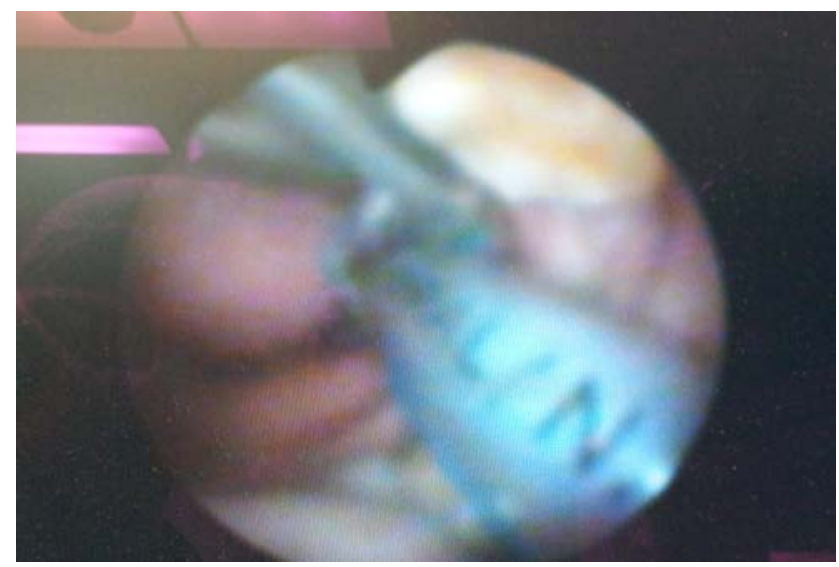

Fig. 1 Fiberoptic view of Ryle's tube knotting around endotracheal tube.

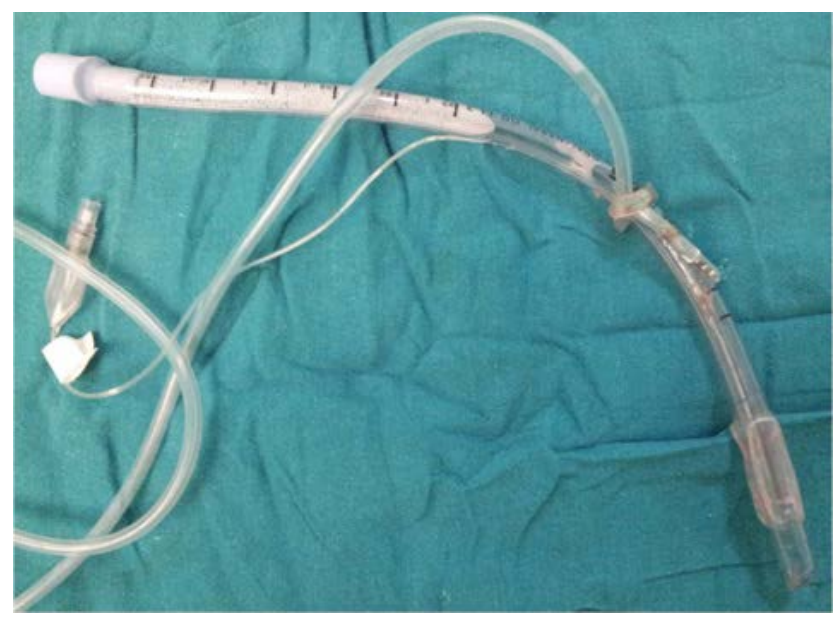

Fig. 2 Ryle's tube knotted around endotracheal view in vitro.

\section{Discussion}

One of the most common invasive procedures performed is insertion of nasogastric tube for gastric suction and feeding. Many different complications of Ryle's tube insertion have been reported in the past, but very rarely similar case reports of Ryle's tube knotting around ETT have been reported in the literature previously. Au-Truong et al, ${ }^{3}$ Hariharan et al, ${ }^{4}$ and Acharya et $\mathrm{al}^{5}$ reported similar incidences of gastric tube knotting around ETT stating no damage to the airway by Ryle's tube knotting. Hariharan et al stated the use of twin Magill's forceps to untie the nasogastric tube knotted around the ETT. In supine, intubated, anesthetized patients, impact of gastric tube on the piriform sinuses and arytenoid cartilages is due to the posterior tilt of intubated larynx and cuffed tracheal tube itself, which interferes with advancement of the gastric tube ${ }^{2}$ and tends to curl and coil within the pharynx. Attempts to withdraw the curled or coiled gastric tube may cause a loop to tighten into a knot, rarely around the ETT in an intubated patient. Hence, care must be taken while doing so.

Many authors have reported different complications of Ryle's tube insertion in intubated patients. Bautista ${ }^{6}$ reported trauma associated with bleeding mainly due to unsuccessful attempts at insertion in intubated patients. Other complications of Ryle's tube insertion reported by Pousman and Koch $^{7}$ were ETT obstruction after orogastric tube placement. Reports of accidental tracheal extubation by Dorsey et $\mathrm{al}^{8}$ and near cardiac arrest by Sinha et $\mathrm{al}^{9}$ in the past have been mentioned, due to nasogastric tube withdrawal. Nasogastric tube lying in right pleural space, left-sided pleural effusion and pneumonia have also been mentioned by Sinha et al. ${ }^{9}$

\section{Alternative Methods for Nasogastric Insertion}

Thus, in difficult cases, alternative methods of Ryle's tube insertion ${ }^{10}$ like neck flexion, intraoral manipulation, head in lateral position as stated by Kumar et al, ${ }^{10}$ digital lateralization of gastric tube, and insertion of gastric tube in prone position${ }^{11}$ have been reported. Ghatak et al ${ }^{12}$ suggested a new technique to insert nasogastric tube in an unconscious intubated 
patient. The use of fiberoptic bronchoscope to assist prevention of knotting is nowadays more common. Knotting of gastric tubes may be prevented by the alternative maneuvers designed to facilitate the placement of nasogastric tube, such as forward displacement of the intubated trachea by external laryngeal maneuver or by using glide scope mentioned by Sahu and Kishore ${ }^{13}$ or lateral neck pressure using fiberoptic bronchoscope suggested by Ozer and Benumof. ${ }^{14}$ Inserting a Fogarty or other types of catheter ${ }^{12}$ through the suction port of the gastric tube to increase its rigidity and lubrication also aids on its further advancement . Lind and Wallace ${ }^{15}$ stated direct guidance of the tube with two fingers in the mouth and use of Magill's forceps with direct laryngoscopic visualization. Use of ETT to place a nasogastric tube has also been used in the past.

\section{Conclusion}

The most important factor is the care, expertise, and eternal vigilance in inserting Ryle's tube in an intubated patient by the anesthesiologist to prevent any complications during the entire procedure.

\section{Conflict of Interest}

None declared.

\section{References}

1 Kubo K, Nakao S, Kawabata Y, Nishimae H, Masuko S, Shingu K. An unusual case of airway obstruction at the tip of an endotracheal tube caused by insertion of a nasogastric tube. J Anesth 2008;22(1):52-54

2 Kiran S, Kaur K. Coiled ERCP catheter in the oral cavity. Internet J Anesthesiol 2009;19(2). Doi: 10.5580/d72

3 Au-Truong X, Lopez G, Joseph NJ, Salem MR. A case of a nasogastric tube knotting around a tracheal tube: detection and management. Anesth Analg 1999;89(6):1583-1584
4 Hariharan U, Bhasin N, Gupta N, Senapati NN, Sanyal K. Ryle's tube knotting around the tracheal tube: twin Magills forceps tour rescue. J Anest \& Intens Care Med 2017;2(2):1-2

5 Acharya G, Arora KK, Kumar D. Nasogastric tube coiled around endotracheal tube. J Anaesthesiol Clin Pharmacol 2014;30(4):584-586

6 Bautista EM. Complications of nasogastric tube insertion. Chest 1988;93(5):1119-1120

7 Pousman RM, Koch SM. Endotracheal tube obstruction after orogastric tube placement. Anesthesiology 1997;87(5): $1247-1248$

8 Dorsey M, Schwinder L, Benumof JL. Unintentional accidental extubation by orogastric tube removal. Anesth Rev 1988;15:30-33

9 Sinha PK, Koshy T, Sivakumar P. Nasogastric tube withdrawal: an unusual cause of accidental extubation and near cardiac arrest. J Cardiothorac Vasc Anesth 2000;2(1):105-107

10 Kumar DSP, Ray S, Shastri P, Rao BK. Gastric tube placement in difficult cases: an extensive review of the alternate methods: The Indian Anaesthetists' Forum October 2008(2). Online ISSN 0973-0311

11 Yamauchi M, Furuse S, Asano M, Watanabe M, Iwasaki S, Namiki A. Insertion of a nasogastric tube with the patient in the prone position. Can J Anaesth 2005;52(10):1106-1107

12 Ghatak T, Samanta S, Baronia AK. A new technique to insert nasogastric tube in an unconscious intubated patient. $\mathrm{N}$ Am J Med Sci 2013;5(1):68-70

13 Sahu S, Kishore K, Sachan V. Chatterjee A. Rare complication of nasogastric tube knotting around endotracheal tube in an anesthetized patient undergoing surgery. Anesth Essays Res 2017;11(1):248-250

14 Ozer S, Benumof JL. Oro-and nasogastric tube passage in intubated patients: fiberoptic description of where they go and how to make them enter the esophagus. Anesthesiology 1999;91(1):137-143

15 Lind LJ, Wallace DH. Submucosal passage of a nasogastric tube complicating attempted intubation during anesthesia. Anesthesiology 1978;49(2):145-147 